\title{
DISCRIMINATION AND ENTREPRENEURSHIP: EVIDENCE FROM LGBT RIGHTS LAWS
}

\author{
RAFFAELE CONTI \\ Catolica Lisbon \\ Palma de Cima, 1649-023 Lisbon, Portugal \\ OLENKA KACPERCZYK \\ London Business School \\ GIOVANNI VALENTINI \\ IESE Business School
}

\section{INTRODUCTION}

Founding a new business is one of the most important features of today's economy. Efforts to increase participation in the entrepreneurial economy have increasingly focused on removing barriers that systematically impede some individuals from launching a new business. Amongst these barriers, discrimination is deemed to be the key obstacle to entrepreneurial entry, as negative beliefs and stereotypes about disadvantaged groups hinder the entry by minority groups. However, where scholars have equated the rise of entrepreneurship with decline in bias, only the demand side of the entrepreneurial process has been examined: that is, instances in which prospective entrepreneurs are subject to discrimination by resource providers. But the decision to enter entrepreneurship is also influenced by the supply-side factors and a growing line of entrepreneurship research suggests that launching a new venture is a function of the availability of individuals willing to occupy entrepreneurial roles. Paid employment - or opportunities within the current workplace or with potential employers - has a profound impact on whether or not an individual chooses to enter entrepreneurship. But entrepreneurship scholars have devoted little attention to the origins of discrimination and the critical distinction between the demand and supply side. As a consequence, our understanding of how efforts to reduce discrimination might influence transition into entrepreneurship remains incomplete. In this study, we shift the focus of current research and propose that the different origins of bias will set off different mechanisms, thus leading to profoundly different outcomes in entrepreneurship.

\section{Antidiscrimination and Entrepreneurial Entry}

Because scholars have identified discrimination to have an enduring, negative impact on startup founding, a logical implication of past studies is that efforts that reduce discrimination will broaden participation in entrepreneurship and increase the rates of entry. However, despite these accounts leading to an expectation that, entrepreneurial foundings should increase in absence of discriminatory behavior, the relationship between discrimination and transition into entrepreneurship remains poorly understood. Where scholars found evidence that discrimination undermines participation in entrepreneurship, they focused only on contexts in which bias originates on the demand side of the entrepreneurial process, or instances in which prospective entrepreneurs seek resources from key providers to explore entrepreneurial opportunities 
(Thornton, 1999). But transition into entrepreneurship is also driven by the supply-side factors, or the willingness of people to leave paid employment to occupy entrepreneurial roles. A growing line of research suggests the critical role of paid employment in influencing the motivation and willingness of individuals to sort into entrepreneurship. This view suggests that the decision to become an entrepreneur is partly a function of a worker's calculus of whether to give up their attachment to paid employment and launch a new venture instead (Hellman, 2008; Kacperczyk, 2012; Sorensen and Sharkey, 2014; Audia and Rider, 2006). Similar to entrepreneurship theories, sociological studies of discrimination have highlighted the crucial role of paid employment in propelling discrimination and imposing constraints on opportunities available to minority groups. Yet, in examining discrimination in entrepreneurship, the extant accounts have rarely integrated these theories and scholars have not conceptualized the distinct origins of bias in an entrepreneurial process.

\section{Paid Employment and Transition into Entrepreneurship}

Although individuals have diverse motives for entering entrepreneurship, there is increasing attention to factors on the supply side of the entrepreneurial process that influence motivation, ability, and willingness to launch a new venture, independent of entrepreneurial opportunities in the market (Thronton, 1999). Scholars have claimed, for example, that entrepreneurship is intertwined with career options in paid employment and is therefore best examined as a career-mobility decision (Kacperczyk 2012, Kacperczyk and Marx 2016, Sorensen and Sharkey 2014). Importantly, employees are more likely to leave paid employment for entrepreneurship when entry is more compelling than alternative career options in the current workplace or with other potential employers (Kacperczyk 2012, Kacperczyk and Marx 2016, Sorensen and Sharkey 2014; Rider et al., 2016). Because people are less inclined to launch new ventures when options with paid employment are more enticing, efforts to reduce employer discrimination might change the relative appeal of entrepreneurship.

\section{Employment Antidiscrimination and Entry into Entrepreneurship}

Sanctions against employer bias might alter a person's choice between paid employment and entrepreneurship by enhancing the relative attractiveness of the former. These initiatives will reduce the inclination for entrepreneurial entry in at least two ways. First, when employers are less likely to reveal bias in assessing minority workers, individuals in these disadvantaged groups will find paid employment relatively more appealing, as advancement options and career prospects appear more equitably distributed in the workplace. Second, efforts to prevent discrimination may suppress entrepreneurial rates by enhancing the perceived attractiveness of paid employment even for those not subject to discrimination per se. Extensive research in sociology and strategy highlights the universal benefits of antidiscrimination, openness, and diversity initiatives. A similar argument - that preventing employer discrimination and promoting diversity enhances the value employees place on paid employment - is also prevalent in the line of research on corporate social responsibility (CSR; Burbano, Mamer, and Snyder, 2013; Flammer and Kacperczyk, 2015). Studies in this vein have suggested that CSR practices, many of which focus on promoting diversity and inclusion, enhance employee commitment and job satisfaction (Dimarco, 1975), in part because firms perceived as being fair and caring toward all groups of employees boost workplace engagement, feelings of inclusion, and the trust 
climate. Efforts to prevent discrimination in the labor market not only might influence entrepreneurial transition rates, but also the new-venture's growth orientation. When the relative appeal of paid employment increases, the threshold for exploring entrepreneurial opportunities will rise, leading to the founding of ventures with higher growth potential. Overall, initiatives that reduce employer discrimination will suppress the rates of entrepreneurship, but enhance growth-orientation of new ventures.

\section{H1: Initiatives to reduce employer discrimination will lead to a decline in the rate of entrepreneurial foundings.}

\section{H2: Initiatives to reduce employer discrimination will lead to an increase in the rate of growth-oriented ventures.}

\section{EMPIRICAL SETTING AND DATA}

The source of exogenous variation we exploit in this paper is the staggered enactment of antidiscrimination laws in different moments in time across different U.S. states. Specifically, we focus on the enactment of antidiscrimination law, the ENDA, which protects workers from employer discrimination based on sexual orientation and gender identity. The District of Columbia was the first to pass such a law in 1977, and by the end of 2009, 20 states had followed suit. The enactment of these laws is suitable for our identification strategy for at least three reasons. First, there is substantial empirical evidence that discrimination based on sexual orientation and gender identity has been an important challenge in the American workplace (e.g., Badgett et al., 2007). Finally, although the enactment of these laws does not allow measuring employer discrimination directly, it gives us a unique opportunity to proxy for the change (i.e., decrease) in the level of discrimination by employers in a given state after enactment.

\section{Dependent Variables}

Entrepreneurial foundings. We obtained data on entrepreneurial foundings from the Longitudinal Business Database (LBD). The LBD provides data on annual employments for every U.S. private sector establishment having a payroll. The underlying data are sourced from U.S. tax records and Census Bureau surveys, and approximately 4 million establishments and 70 million employees are included in the average year. The LBD includes complete accounting of very small firms and establishments, which are often excluded or subsampled in typical corporate surveys. The LBD also lists physical locations of establishments rather than states of incorporation. Following Kerr and Nanda (2009), for each establishment we define its year of entry as the first year of positive employment. Entrepreneurial foundings is measured as the total number of new, stand-alone establishments in a given state and year. Data from LBD are available from 1977 to 2011 .

Growth orientation. First, we proxy for growth orientation in a given state using the average amount of venture capital (VC) funding that a new venture has received, calculated as the total amount of VC investments in a given state-year - from 1980 to 2011 - normalized by the number of new entrants in the same state-year. The VC data (by location of investee company) were retrieved from Thomson Reuters' VentureXpert. The second measure of growth orientation that we consider is the propensity of young firms to file for patents proxied for by the 
number of patent applications filed by new assignees in a given state-year - from 1977 to 2004 normalized by the number of new entrants. New firms that file for patents are more likely to be (a) endowed with superior technologies and (b) better able to capture the value that their technologies create. Data on patents are retrieved from the NBER dataset.

Treatment Dummy. We exploit the staggered enactment of laws prevent discrimination in the labor market and promote the protection of gay and gender identity rights. Following the relevant literature (e.g., Kerr and Nanda, 2009; Flammer and Kacperczyk, 2015), for the treated states our independent variable takes the value 1 starting from the year after a given state has enacted an antidiscrimination law and 0 before that, and is always equal to 0 for the control states, or those that did not implement the antidiscrimination law.

\section{METHODOLOGY}

To examine the impact of employer antidiscrimination on entrepreneurship following the passage of the antidiscrimination laws, we use a difference-in-differences (diff-in-diffs) methodology based on the 21 treatments listed in table 1 . The unit of analysis of our empirical analyses, therefore, is state-year. Our methodology is an application of the difference-indifferences in the presence of staggered treatments at the state level. Specifically, our main specifications will take the form:

$$
\mathrm{Y}_{\mathrm{st}}=f\left(\varphi_{\mathrm{s}}+\tau_{\mathrm{t}}+\beta_{\mathrm{AD}} \mathrm{AD}_{\mathrm{st}}+\boldsymbol{\beta}_{\mathrm{CV}} \mathbf{C} \mathbf{V}_{\mathrm{st}-1}\right)
$$

where $\mathrm{AD}$ is the "treatment dummy" - a dummy variable equal to 1 if the company is located in a state that has enacted the antidiscrimination law by year $t . \mathbf{C V}$ is a vector of control variables, and $\varphi_{\mathrm{s}}$ and $\tau_{\mathrm{t}}$ are state and year fixed effects. The functional form of $f()$ that we implement depends on the nature of the dependent variable Y. Errors are always clustered at the state level, to address potential serial correlation concerns. The coefficient of interest is $\beta_{A D}$, which measures the effect of antidiscrimination law on our dependent variable. For instance, H1 predicts that $\beta_{A D}$ should be negative and significant when $\mathrm{Y}$ is the number of entrepreneurial foundings.

\section{MAIN RESULTS}

We begin by evaluating the effect of antidiscrimination laws on the number of new entrants. Since entrepreneurial foundings is a count variable, we use a Poisson (fixed effects) regression. Table 1 reports the results of this basic estimation. In these analyses (and in most of the following ones), control states - states that never change their status with respect to antidiscrimination policies - are observed over the complete time frame of the data, from 1977 to 2011; by contrast, treated states - states that enact new antidiscrimination policies - are observed for two different time-windows around the first year after the enactment: 5 years in model 1 and 10 years in model 2 of table 1. These specifications ensure that treated states are considered for a limited and homogenous number of years. Given the staggered introduction of laws and the relatively long time span of our dataset, it is important to minimize the possibility that the treatment dummies absorb other events or noise due to a substantial number of years following treatment. Overall, then, the treated states have equal "weight" in our estimation. Both specifications reported in table 1 show that the enactment of ENDAs has a negative and statistically significant effect on entrepreneurial foundings. These results thus lend support to H1 
and suggest that a decrease in employer discrimination negatively affects new-firm entry: considering specification 1, introducing an antidiscrimination law diminishes entrepreneurial foundings by about $8 \%$.

\section{Table 1 about here}

$\mathrm{H} 2$ suggested that antidiscrimination laws increase the growth orientation of new entrants. To test this hypothesis, we use a linear fixed-effects estimation, as both of our proxies for new ventures' growth orientation are continuous variables. The estimates for growth orientation are reported in table 2, with VC funding in models 1 and 2, and patents in models 3 and 4. For both measures, we consider the time window of 10 years before and after treatment as well as 5 years before and after treatment. Consistent with our predictions, we find that while the enactment of ENDAs reduces overall new-firm entry, it nevertheless promotes entry of highgrowth startups. The parameter estimate of the treatment dummy is positive and statistically significant across all specifications with the exception of specification 4 , where it is borderline significant at conventional levels. These results thus broadly support $\mathrm{H} 2$ and suggest that the enactment of antidiscrimination laws increases the opportunity cost of entering entrepreneurship by enhancing the attractiveness of options within paid employment. As a consequence, those who turn to entrepreneurship do so only when they perceive high-value, or potentially highgrowth, entrepreneurial opportunities. In sum, we find support for the key predictions of our study.

Table 2 about here

\section{DISCUSSION}

Whereas past studies implied a positive association between entrepreneurial founding and eliminating discrimination, their overarching conclusions are based on discriminatory behaviors arising on the demand side of the entrepreneurial process, or the decisions of actors providing entrepreneurs with the needed resources to start a business. We build on the career perspective on entrepreneurship and theorize that efforts to prevent discrimination hinder entry into entrepreneurship when such initiatives pertain to the supply side of the entrepreneurial process, or the decision to transition from paid employment into entrepreneurship. Lending support to this theory, our findings indicate that antidiscrimination laws that prevent employer discrimination based on sexual orientation and gender identity have a negative effect on entrepreneurial foundings. This result is consistent with our argument that antidiscrimination initiatives, when applied to the supply side, enhance the attractiveness of paid employment relative to entrepreneurship, increasing the opportunity cost of leaving to launch a new venture. As further evidence, our study shows that as the threshold for giving up paid employment for entrepreneurship increases, the average growth potential of a new venture increases. Together, our insights indicate that although some antidiscrimination initiatives may boost entrepreneurial rates, others may have a more nuanced impact on entrepreneurship by influencing whether people are willing to give up paid employment in the first place.

REFERENCES AVAILABLE FROM THE AUTHORS 
Table 1. Effect of Antidiscrimination Laws on the Rate of Entrepreneurial Foundings (Poisson Specification)

\begin{tabular}{lcc}
\hline VARIABLES & $\begin{array}{c}(1) \\
\text { foundings } \\
+/-10 \text { years }\end{array}$ & $\begin{array}{c}(2) \\
\text { foundings } \\
+/ 5 \text { years }\end{array}$ \\
\hline Antidiscrimination law & $-0.080^{* * *}$ & $-0.072^{* * *}$ \\
GDP per capita & $(0.031)$ & $(0.027)$ \\
& $0.018^{* * *}$ & $0.018^{* * *}$ \\
Firms & $(0.003)$ & $(0.003)$ \\
& $0.002^{* *}$ & $0.002^{* *}$ \\
Observations & $(0.001)$ & $(0.001)$ \\
State FEs & 1,399 & 1,236 \\
Year FEs & Yes & Yes \\
Log-likelihood & Yes & Yes \\
\hline No: Res & -60484.167 & -54156.186 \\
\hline
\end{tabular}

Note: Robust standard errors clustered by state in parentheses. ${ }^{* * *} \mathrm{p}<0.01,{ }^{* *} \mathrm{p}<0.05,{ }^{*} \mathrm{p}<0.1$

Table 2. Effect of Antidiscrimination Laws on Growth Orientation (OLS Specifications)

\begin{tabular}{lcccc}
\hline VARIABLES & $\begin{array}{c}(1) \\
\text { (Innovation) } \\
+/-10 \text { years }\end{array}$ & $\begin{array}{c}(2) \\
\text { Innovation) } \\
+/ 5 \text { years }\end{array}$ & $\begin{array}{c}(3) \\
\text { (VC) } \\
+/-10 \text { years }\end{array}$ & $\begin{array}{c}(4) \\
\text { (VC) } \\
+/-5 \text { years }\end{array}$ \\
\hline Antidiscrimination law & $0.003^{* * *}$ & $0.002^{* * *}$ & $0.023^{* *}$ & 0.008 \\
GDP per capita & $(0.001)$ & $(0.001)$ & $(0.009)$ & $(0.005)$ \\
& $0.000^{* * *}$ & $0.000^{* * *}$ & $0.002^{* *}$ & $0.001^{* * *}$ \\
Firms & $(0.000)$ & $(0.000)$ & $(0.001)$ & $(0.000)$ \\
& 0.000 & 0.000 & 0.000 & 0.000 \\
Observations & $(0.000)$ & $(0.000)$ & $(0.000)$ & $(0.000)$ \\
State FEs & 1,113 & 970 & 1,335 & 1,172 \\
Year FEs & Yes & Yes & Yes & Yes \\
R-squared & Yes & Yes & Yes & Yes \\
\hline Nes & 0.629 & 0.622 & 0.335 & 0.433 \\
\hline
\end{tabular}

Note: Robust standard errors clustered by state in parentheses. ${ }^{* * *} \mathrm{p}<0.01,{ }^{* *} \mathrm{p}<0.05,{ }^{*} \mathrm{p}<0.1$ 